\title{
Limited geographic genetic structure detected in a widespread Palearctic corvid, Nucifraga caryocatactes
}

The Eurasian or spotted nutcracker (Nucifraga caryocatactes) is a widespread resident corvid found throughout the Palearctic from Central Europe to Japan. Characterized by periodic bouts of irruptive dispersal in search of Pinus seed crops, this species has potential for high levels of gene flow across its range. Previous analysis of 11 individuals did not find significant range-wide population genetic structure. We investigated population structure using 924 base pairs of mitochondrial DNA control region sequence data from 62 individuals from 12 populations distributed throughout the nutcracker's range. We complemented this analysis by incorporating additional genetic data from previously published sequences. High levels of genetic diversity and limited population genetic structure were detected suggesting that potential barriers to dispersal do not restrict gene flow in nutcrackers. 
1 TITLE: Limited geographic genetic structure detected in a widespread Palearctic corvid,

2 Nucifraga caryocatactes

3 Authors: Kimberly M. Dohms ${ }^{1}$ and Theresa M. Burg ${ }^{1}$

4 AfFILIATION: 'Biological Sciences, University of Lethbridge, 4401 University Dr. W,

5 Lethbridge, $\mathrm{AB}$, Canada, T1K 3M4

6 CORRESPONDING AUTHOR: Kimberly M. Dohms; Biological Sciences, University of Lethbridge,

74401 University Drive W, Lethbridge, AB, Canada. T1K 3M4; Ph: 1-403-332-5213; Fax: 1-403-

8 329-2082; kim.dohms@uleth.ca 


\section{Introduction}

10 In Eurasia, phylogeographic studies of many widespread vertebrate species have revealed a

11 variety of geographical patterns of population structure influenced by current and historical

12 landscapes, with little overall consensus among species. Using mitochondrial DNA, east-west

13 splits have been documented for a variety of vertebrates including bats (Flanders et al. 2009), and

14 several avian species (e.g. Eurasian magpie (Pica pica; Kryukov et al. 2004), rook (Corvus

15 frugilegus; Haring et al. 2007), and red-breasted flycatcher (Ficedula parva; Zink et al. 2008)).

16 For other species, multiple splits have occurred (e.g. root vole (Microtus oeconomus; Brunhoff et

17 al. 2003) and reed bunting (Emberiza schoeniclus; Zink et al. 2008)), or peninsula populations are

18 isolated (e.g. great bustard (Otis tarda; Pitra et al. 2000)). In contrast, little population structure

19 has been detected in some widespread species, such as otters (Lutra lutra; Ferrando et al. 2004)

20 and several avifauna species (e.g. great spotted woodpecker (Dendrocopos major; Zink et al.

21 2002), common sandpiper (Actitis hypoleucos; Zink et al. 2008), and Eurasian magpie (Pica pica;

22 Zhang et al. 2012)). Some of the observed phylogeographic patterns have been explained by post-

23 glacial colonization from single or multiple refugia, but may also be influenced by barriers to

24 dispersal, such as mountain ranges (e.g. Ural Mountains), large areas of inhospitable habitat (e.g.

25 Tibetan Plateau), or large bodies of water.

26 The Eurasian nutcracker (Nucifraga caryocatactes, Linnaeus, 1758) is a corvid with a widespread

27 Palearctic distribution. Although generally classified as a resident species of continental

28 coniferous forests, nutcrackers are known to irruptively disperse to take advantage of mast

29 conifer seed crops (Haring et al. 2007), similar to its North American sister species, Clark's

30 nutcracker (N. columbiana; Tomback 1998). Strong geographic genetic structure has not been

31 found in Clark's nutcracker, despite numerous potential physical barriers to dispersal and thus

32 gene flow (Dohms and Burg 2013). A previous study by Haring and colleagues (2007) found no 
33 population structure in N. caryocatactes throughout Eurasia. However, Haring et al. (2007) only

34 used 11 specimens, thus additional data may shed further light on nutcracker population genetic 35 structure.

36 In this study, we use a highly variable and rapidly evolving mitochondrial DNA marker, the

37 control region, to further investigate population structure of $N$. caryocatactes in Eurasia. Based

38 on the ecology of this species, we predict little range-wide population genetic structure.

\section{Materials \& Methods}

$40 \quad$ Samples

41 Tissue samples $(n=62)$ collected throughout the Eurasian nutcracker's range (Fig. 1) were

42 acquired from the Burke Museum of Natural History and Culture at the University of Washington

43 (Supplemental Table S1). Previously published control region $(\mathrm{CR})$ sequences $(\mathrm{n}=11)$ were

44 obtained from GenBank (EU070770 and EU070886-EU070895; Haring et al. 2007).

\section{DNA extraction, PCR amplification, and sequencing}

46 DNA from muscle samples stored in ethanol or lysis buffer was extracted using a modified

47 Chelex extraction protocol (Walsh et al. 1991; Burg \& Croxall, 2001). A 924 bp fragment

48 starting at position 46 of the control region (CR; Saunders and Edwards 2000) was amplified

49 using two primers: L46 SJ (5'-TTT GGC TAT GTA TTT CTT TGC-3'; developed for Steller's

50 jay (Cyanocitta stelleri; Birt \& Lemmen, unpublished)) and H1030 JCR 18 (5'-TAA ATG ATT

51 TGG ACA ATC TAG G-3'; developed for Aphelocoma jays (Saunders and Edwards 2000)). DNA

52 was amplified in a Master gradient thermocycler (Eppendorf) in $25 \mathrm{~L}$ reactions with $1 \mathrm{x}$ goTaq

53 Flexi buffer (Promega), $2.5 \mathrm{mM} \mathrm{MgCl}_{2}, 200 \mathrm{M}$ dNTP, $0.4 \mathrm{M}$ of each primer, and 1 unit goTaq 
54 Flexi taq polymerase (Promega). DNA sequencing was performed on an ABI 3730xl DNA

55 Analyzer at McGill University and Génome Québec Innovation Centre.

56

57

58

59

60

61

62

63

64 Results

65 Genetic analyses

66

67

68

69

70

71

72

\section{Alignment and analysis}

We edited and aligned sequences from chromatograms and an overlapping subset of $305 \mathrm{bp}$ from previously published CR sequences from GenBank (Haring et al. 2007) using MEGA v5.0

(Tamura et al. 2007). Two unrooted statistical parsimony networks (95\% probability) were constructed with TCS v1.21 (Clement et al. 2000): one for the samples sequenced as part of this study (924 bp) and a second network that for the 305 bp common fragment (this study; Haring et al. 2007). We calculated the number of haplotypes $\left(H_{n}\right)$, haplotype diversity $\left(H_{d}\right)$, and nucleotide diversity $(\pi)$ for museum samples using DnaSP v5.10 (Rozas et al. 2003).

We sequenced and aligned the 924 bp control region (CR) sequences for 62 individuals from 12 populations (Table 1; GenBank accession nos. XXXX-XXXX). We aligned 11 additional GenBank sequences (Haring et al. 2007) with sequences from our samples and obtained a 305 bp area of overlap. Statistical parsimony networks did not suggest strong geographic structure for the 924 bp sequence (Fig. 2), nor for the larger dataset using the overlapping 305 bp fragment for all 73 individuals (Fig. 3). Ncarcar5 could not be connected to the network in the larger dataset, which was also found by Haring et al. (2007).

73 For the 62 individuals we sequenced, we found 45 unique haplotypes and high levels of genetic

74 diversity in most populations (Table 1). We found 57 polymorphic sites within the 924 bp

75 sequence and 22 within the 305 bp sequence. Haplotype diversity for the 924 bp sequence varied 
76 from 0.000 (Ola River headwaters (OR)) to 1.000 (five populations), and all but the OR

77 population had a haplotype diversity equal to or greater than 0.800 (Table 1 ). Nucleotide diversity

78 ranged from $0.00000(\mathrm{OR})$ to $0.00993\left(\mathrm{PK}\right.$; Table 1). Overall haplotype diversity $\left(\mathrm{H}_{\mathrm{d}}\right) 0.967$ and

79 nucleotide diversity $(\pi)$ was 0.00537 .

\section{Discussion}

81 As predicted, analyses of Eurasian nutcracker mitochondrial DNA control region sequences did 82 not detect significant population genetic structure. All populations except nutcrackers from the

83 Ola River headwaters (OR; $n=2)$ exhibited high haplotype diversity and relatively high

84 nucleotide diversity. No geographic clustering was observed in statistical parsimony networks,

85 even when integrating samples from the western part of the range. Despite potential barriers to

86 dispersal for this species, such as isolation on an island (e.g. Sakhalin Oblast (SO)) or peninsula

87 (e.g. Kamtchatka (KA)), most populations of $N$. caryocatactes do not appear to be geographically

88 differentiated from each other, likely due to gene flow during irruptive dispersal in search of mast

89 pine seed crops. Overall, our work supports that done by Haring et al. (2007) where no significant

90 split was seen between the east and west for nutcrackers and is similar to the pattern found in $N$.

91 caryocatactes sister species, N. columbiana (Dohms and Burg 2013).

92 Compared to Haring et al. (2007), our study found a higher level of haplotype diversity $\left(\mathrm{H}_{\mathrm{d}}=\right.$

930.967 vs 0.844 and $\pi=0.00537$ vs 0.00279 ). This may be due to the portion of control region

94 sequenced and the larger sample sizes used in this study. The sequences obtained from our

95 samples are predominantly composed of domains I and II of the mtDNA control region (Saunders

96 and Edwards 2000), whereas Haring et al. (2007) sequenced primarily domain II, which is

97 considered less variable (Ruokonen and Kvist 2002). 
98 Haring et al. (2007) state that low genetic diversity may suggest a bottleneck in this species and a

99 single glacial refugium. With high levels of nucleotide and haplotype diversity, our findings do

100 not support a historical bottleneck but rather point toward two possible scenarios: multiple

101 refugia with gene flow or a single refugium with large population size during expansion.

102 Expansion from multiple refugia with gene flow after colonization can produce similar genetic

103 patterns to those in species that expanded slowly from a single refugium with a large population

104 size, retaining high genetic diversity and limited geographic structuring of populations (Hewitt

105 2004). Given the dispersal potential of nutcrackers, it is possible that a large population

106 expanded out of a single refugium, but it is equally plausible that expansion occurred out of

107 multiple refugia with subsequent gene flow between geographically distinct populations due to

108 irruptive dispersal events. The multiple refugia scenario could have produced the large number of

109 haplotypes, often with high levels of sequence divergence pattern seen here. For example,

110 individuals from Primorsky Kray (PK) are found scattered throughout the parsimony network

111 (Fig. 2), in some cases with a large number of mutations between PK individuals and other

112 haplotypes, yet found clustered with geographically distant individuals from Irkutsk Oblast (KD)

113 and KA. This level of divergence is often associated with isolation in and subsequent

114 colonization from multiple refugia (Hewitt 2004). With the high haplotype diversity across all

115 populations, it is not possible to determine which population(s), if any sampled here, may be in

116 the location of the original refugium or refugia. Without additional present day samples from the

117 Alps and Himalaya Mountain ranges, it is difficult to tell using genetic signatures if these areas

118 served as refugia for nutcrackers during the LGM.

119

120 Our findings do not support a single refugium in the Altai Mountains of southern Mongolia, as

121 postulated by Haring et al. (2007). Rather, our data show highly divergent haplotypes which

122 could be the result of prolonged isolation in multiple refugia. Scots pine (Pinus sylvestris), an 
123 important source of food for nutcrackers, is thought to have survived in refugia near the Alps

124 (Naydenov et al. 2007) and in the east, unglaciated portions of the Himalayas could have served

125 as a refugium for high latitude species (Zhuo et al. 1998; Owen et al. 2002). Alternatively, high

126 levels of plant endemism have been found in the mountains of southern and eastern China,

127 suggestive of long-term suitable habitats (Zhuo et al. 1998). Nutcrackers may have survived in

128 these bands of suitable habitat in the southwest and southeast areas of Eurasia and expanded

129 northward from multiple refugia as glaciers retreated.

\section{Conclusions}

131 Overall, Eurasian nutcrackers exhibit limited geographic genetic structure throughout their range,

132 as might be expected from a resident bird with irruptive dispersal patterns. Our study found high

133 genetic diversity, which suggests that a population bottleneck has not occurred in this species as

134 previously hypothesized. A more detailed phylogeographical study could include additional

135 genetic sampling from northern and southern parts of $N$. caryocatactes' range to further

136 investigate structure across the range of this species.

\section{Acknowledgements}

138 We gratefully acknowledge the assistance of Sharon Birks and the Burke Museum of Natural 139 History and Culture - University of Washington; without tissue samples from their collection, 140 this study would not have been possible. 
142 Brunhoff, C, Galbreath, KE, Fedorov, VB, Cook, JA, Jaarola, M. 2003. Holarctic phylogeography of the root vole (Microtus oeconomus): implications for late Quaternary biogeography of high latitudes. Molecular Ecology 12:957-968.

Clement, M, Posada, D, Crandall, KA. 2000. TCS: A computer program to estimate gene genealogies. Molecular Ecology 9:1657-1659.

Dohms, KM, Burg, TM. 2013. Molecular markers reveal limited population genetic structure in a North American corvid, Clark's Nutcracker (Nucifraga columbiana). PLoS One 8:e79621.

Ferrando, A, Ponsa, M, Marmi, J, Domingo-Roura, X. 2004. Eurasian otters, Lutra lutra, have a dominant mtDNA haplotype from the Iberian Peninsula to Scandinavia. Journal of Heredity 95:430-435.

Flanders, J, Jones, G, Benda, P, Dietz, C, Zhang, S, Li, G, Sharifi, M, Rossiter, SJ. 2009. Phylogeography of the greater horseshoe bat, Rhinolophus ferrumequinum: contrasting results from mitochondrial and microsatellite data. Molecular Ecology 18:306-318.

Haring, E, Gamauf, A, Kryukov, A. 2007. Phylogeographic patterns in widespread corvid birds. Molecular Phylogenetics and Evolution 45:840-862.

Kryukov, A, Iwasa, MA, Kakizawa, R, Suzuki, H, Pinsker, W, Haring, E. 2004. Synchronic eastwest divergence in azure-winged magpies (Cyanopica cyanus) and magpies (Pica pica). Journal of Zoological Systematics and Evolutionary Research 42:342-351.

Naydenov, K, Senneville, S, Beaulieu, J, Tremblay, F, Bousquet, J. 2007. Glacial vicariance in

Owen, LA, Finkel, RC, Caffee, MW. 2002. A note on the extent of glaciation throughout the Himalaya during the global Last Glacial Maximum. Quaternary Science Reviews 21:147-157.

Pitra, C, Lieckfeldt, D, Alonso, JC. 2000. Population subdivision in Europe's great bustard inferred from mitochondrial and nuclear DNA sequence variation. Molecular Ecology 9:11651170 .

Rozas, J, Sánchez-DelBarrio, JC, Messeguer, X, Rozas, R. 2003. DnaSP, DNA polymorphism analyses by the coalescent and other methods. Bioinformatics 19:2496-2497.

Ruokonen, M, Kvist, L. 2002. Structure and evolution of the avian mitochondrial control region. Molecular Phylogenetics and Evolution 23:422-432.

Saunders, MA, Edwards, SV. 2000. Dynamics and phylogenetic implications of mtDNA control region sequences in New World jays (Aves: Corvidae). Journal of Molecular Evolution 51:97109. 
176 Tamura, K, Dudley, J, Nei, M, Kumar, S. 2007. MEGA4: molecular evolutionary genetics

177 analysis (MEGA) software version 4.0. Molecular biology and evolution 24:1596-1599.

178 Tomback, DF. 1998. Clark's nutcracker (Nucifraga columbiana). The Birds of North America 24.

179 Walsh, PS, Metzger, DA, Higuchi, R. 1991. Chelex 100 as a medium for simple extraction of 180 DNA for PCR-based typing from forensic material. Biotechniques 10:506-513.

181 Zhang, R, Song, G, Qu, Y, Alstrom, P, Ramos, R, Xing, X, Ericson, PG, Fjeldsa, J, Wang, H, 182 Yang, X, Kristin, A, Shestopalov, AM, Choe, JC, Lei, F. 2012. Comparative phylogeography 183 of two widespread magpies: importance of habitat preference and breeding behavior on 184 genetic structure in China. Molecular Phylogenetics and Evolution 65:562-572.

185 Zhuo, Z, Baoyin, Y, Petit-Maire, N. 1998. Paleoenvironments in China during the Last Glacial 186 Maximum and the Holocene optimum. Episodes 21:152-158.

187 Zink, RM, Drovetski, SV, Rohwer, S. 2002. Phylogeographic patterns in the great spotted 188 woodpecker Dendrocopos major across Eurasia. Journal of Avian Biology 33:175-178.

189 Zink, RM, Pavlova, A, Drovetski, S, Rohwer, S. 2008. Mitochondrial phylogeographies of five 190 widespread Eurasian bird species. Journal of Ornithology 149:399-413. 


\section{Figure 1}

Nutcracker tissue sample locations throughout Eurasia

Black squares denote locations; corresponding abbreviations are labelled beside squares.

Refer to Table 1 and Supplementary Table S1 for further location information. Black

diamonds denote locations of previously published partial control region sequences obtained from GenBank with corresponding sample codes from Haring et al. (2007).

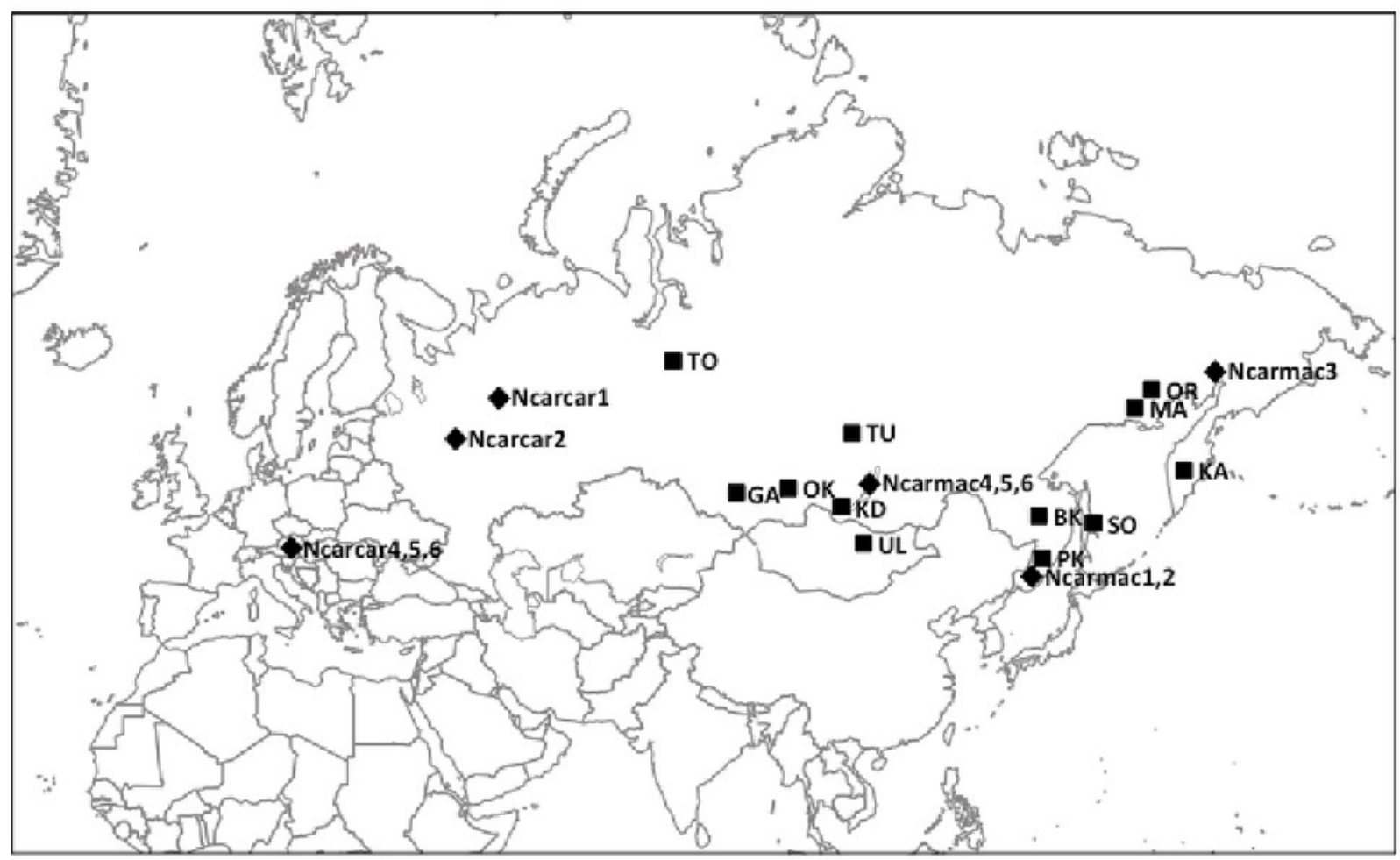




\section{Figure 2}

Statistical parsimony network for 924 bp mitochondrial DNA sequence

Statistical parsimony network of Nucifraga caryocatactes for 924 bp of the mitochondrial DNA control region sequenced from museum samples $(n=62)$. Each square represents one individual and colours correspond to author-defined populations, as per figure legend. Circles indicate inferred haplotypes. Refer to Table 1 for population abbreviations.

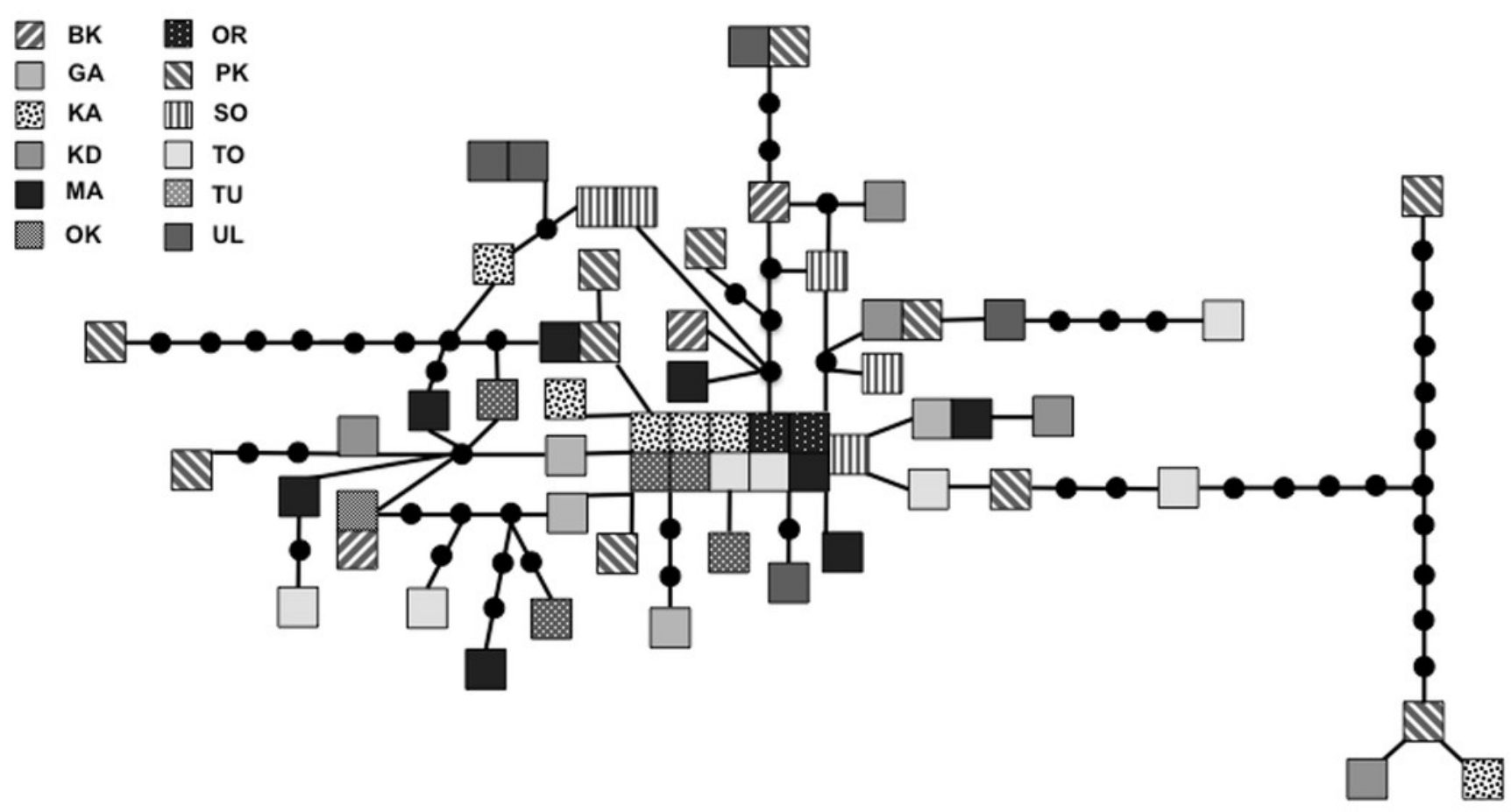




\section{Figure 3}

Statistical parsimony network of $305 \mathrm{bp}$ mitochondrial DNA sequence

Statistical parsimony network of Nucifraga caryocatactes for overlapping sequences of 305 bp of the mitochondrial control region (Domain II) sequenced from museum samples ( $n=62$ ) and GenBank sequences ( $n=11$; Haring et al., 2007 ). Each coloured square represents one individual and colours correspond to author-defined populations. Black solid circles indicate inferred haplotypes. Open circles represent haplotypes; text in circles represents GenBank sequences as per Fig. 1 and Haring et al. (2007). Refer to Table 1 for population abbreviations found in the legend.

\begin{tabular}{l}
$\square$ BK \\
$\square$ GA \\
KA OR \\
$\square$ KD \\
$\square$ MA \\
$\square$ TO \\
$\square$ OK \\
\hline TU
\end{tabular}

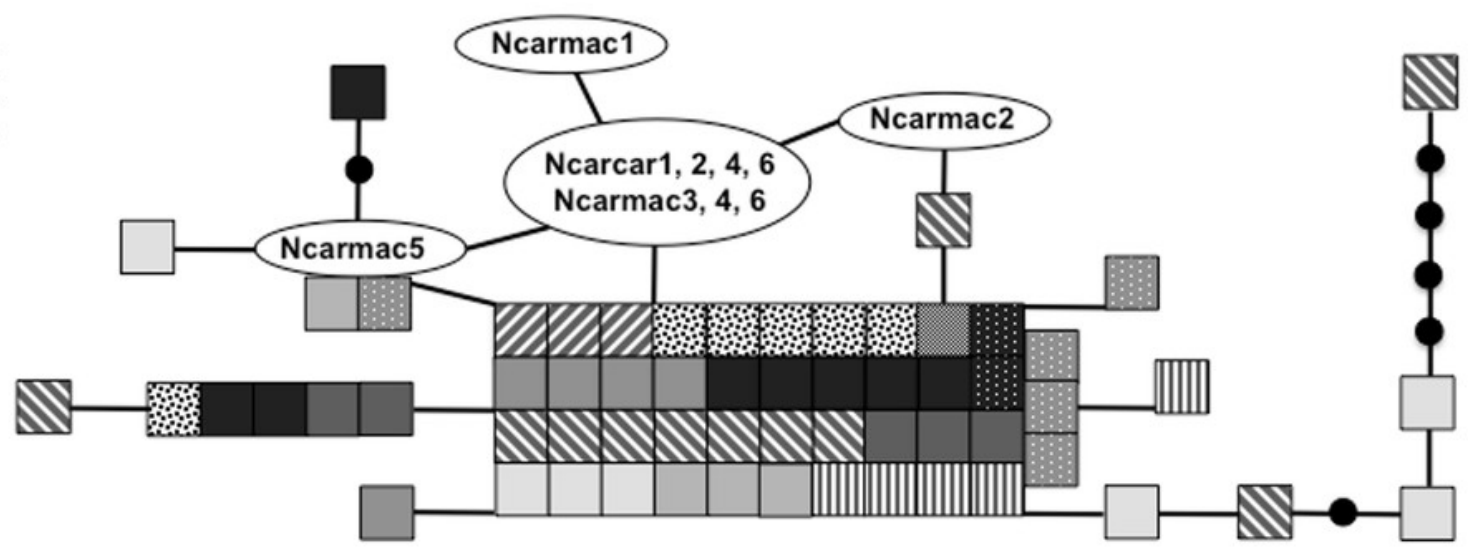




\section{Table 1 (on next page)}

Diversity of a 924 bp mitochondrial DNA sequence

Haplotype diversity for a 924 bp fragment of mtDNA control region from 12 populations of Nucifraga caryocatactes throughout Eurasia. $n=$ number of individuals in population, $\mathrm{H}_{n}=$ number of haplotypes, $H_{d}=$ haplotype diversity, and $\pi=$ nucleotide diversity within the population. 


\begin{tabular}{|c|c|c|c|c|c|}
\hline Population & Location & $n$ & $\mathbf{H}_{\mathrm{n}}$ & $\mathbf{H}_{\mathrm{d}}$ & $\pi$ \\
\hline BK & Badzhal'skiy Krebet, Russia & 3 & 3 & 1.00 & 0.00361 \\
\hline GA & Gorno-Altaysk, Russia & 4 & 4 & $\begin{array}{r}0 \\
1.00\end{array}$ & 0.00328 \\
\hline KA & Kamchatka, Russia & 6 & 4 & $\begin{array}{r}0 \\
0.80\end{array}$ & 0.00369 \\
\hline KD & Irkutsk Oblast, Russia & 5 & 5 & $\begin{array}{r}0 \\
1.00\end{array}$ & 0.00523 \\
\hline MA & Magadanskaya Oblast, Russia & 8 & 8 & $\begin{array}{r}0 \\
1.00\end{array}$ & 0.00397 \\
\hline & & & & 0 & \\
\hline $\begin{array}{l}\mathrm{OK} \\
\mathrm{OR}\end{array}$ & $\begin{array}{l}\text { Kyzyl, Russia } \\
\text { Ola River headwaters, Russia }\end{array}$ & $\begin{array}{l}1 \\
2\end{array}$ & $\begin{array}{l}1 \\
1\end{array}$ & 0.00 & $0.0000 \overline{-}$ \\
\hline PK & Primorsky Kray, Russia & 11 & 11 & $\begin{array}{r}0 \\
1.00\end{array}$ & 0.00993 \\
\hline SO & Sakhalinksya Oblast, Russia & 5 & 4 & $\begin{array}{r}0 \\
0.90\end{array}$ & 0.00195 \\
\hline TO & Tyumenskaya Oblast, Russia & 7 & 6 & $\begin{array}{r}0 \\
0.95\end{array}$ & 0.00622 \\
\hline $\mathrm{TU}$ & Irkutsk Oblast, Russia & 5 & 4 & $\begin{array}{r}2 \\
0.90\end{array}$ & 0.00326 \\
\hline UL & Ulaanbaatar, Mongolia & 5 & 4 & $\begin{array}{r}0 \\
0.90\end{array}$ & 0.00611 \\
\hline Overall & & 62 & 45 & $\begin{array}{r}0 \\
0.96\end{array}$ & 0.00537 \\
\hline
\end{tabular}

